Original Article

\title{
Purification and Characterization of Chitinase from the Nematode - Fungus Paecilomyces sp. P1
}

\author{
Chu Thanh Binh ${ }^{1}$, Nguyen Phuong Nhue ${ }^{2}$, Ho Tuyen ${ }^{2}$, Bui Thi Viet $\mathrm{Ha}^{3, *}$ \\ ${ }^{1}$ Vietnam - Russian Tropical Center, 63 Nguyen Van Huyen, Hanoi, Vietnam \\ ${ }^{2}$ Institute of Biotechnology, VAST, 18 Hoang Quoc Viet, Hanoi, Vietnam \\ ${ }^{3}$ Center for Life Science Research, Faculty of Biology, VNU University of Science, \\ 334 Nguyen Trai, Hanoi, Vietnam
}

Received 26 December 2018

Revised 27 February 2019; Accepted 08 March 2019

\begin{abstract}
The nematophagous - fungi Paecilomyces sp. are currently developed as a biocontrol agent against plant parasitic nematodes (Khan et al., 2003; Yang et al., 2007). Biological control agents can infiltrate certain nematode sites and destroy them by producing some enzymes including chitinase (Khadijeh et al., 2017). This paper discusses the purification and determination of the chitinase activity from Paecilomyces sp. P1. With Lugol reagent, chitinase of this strain was characterized by diffusion on agar plate. Chitinase specific activity was determined by measuring the release of reducing saccharides from colloidal chitin by the $\mathrm{N}$-acetyl-glucosamine-dinitrosalicylate method at $540 \mathrm{~nm}$. By using the saturated $\left(\mathrm{NH}_{4}\right)_{2} \mathrm{SO}_{4}$ precipitation at $65 \%$ concentration, DEAE A50 ion exchanges chromatography and SDS - PAGE concentration of $12.5 \%$; chitinase molecules weigh nearly $50 \mathrm{kDa}$, having a specific activity of $133.3 \mathrm{U} / \mathrm{mg}, 2.1$-fold higher than that of supernatant. Furthermore, tested with the nematode Meloidogyne sp., the ability to kill nematodes of Paecilomyces sp. P1 reached 58\% efficiency in 96h. These results are a scientific basis for the application of Paecilomyces sp. P1 in the production of nematode insecticides.
\end{abstract}

Keywords: Paecilomyces sp. P1, chitinase, purify, biocontrol, Meloidogyne sp.

\footnotetext{
${ }^{*}$ Corresponding author.

Email address: buithivietha@gmail.com

https://doi.org/10.25073/2588-1140/vnunst.4851.
} 


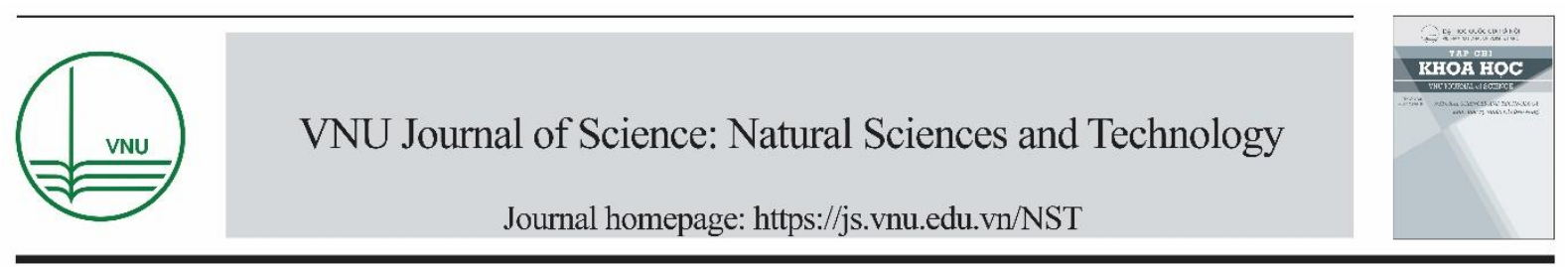

\title{
Tinh sạch và xác định hoạt tính chitinase từ nấm diệt tuyến trùng Paecilomyces sp. P1
}

\author{
Chu Thanh Bình ${ }^{1}$, Nguyễn Phương Nhuệ $\hat{e}^{2}$, Hồ Tuyên ${ }^{2}$, Bùi Thị Việt Hà ${ }^{3, *}$ \\ ${ }^{1}$ Trung tâm Nhiệt đới Việt - Nga, 63 Nguyễn Văn Huyên, Hà Nội, Việt Nam \\ ${ }^{2}$ Viện Công nghệ sinh học, Viện HLKH\&CNVN, 18 Hoàng Quốc Việt, Hà Nội, Việt Nam \\ ${ }^{3}$ Trung tâm Nghiên cứu Khoa học sụ sống, Khoa Sinh học, Truờng Đại học Khoa học Tụ nhiên, \\ ĐHQGHN, 334 Nguyễn Trãi, Hà Nội, Việt Nam \\ Nhận ngày 26 tháng 12 năm 2018 \\ Chỉnh sửa ngày 27 tháng 02 năm 2019; Chấp nhận đăng ngày 08 tháng 03 năm 2019
}

Tóm tắt: Nấm sợi Paecilomyces sp. hiện đang được nghiên cứu như là một tác nhân kiểm soát sinh học chống lại tuyến trùng gây hại thực vật [1]. Tác nhân sinh học có thể xâm nhập vào một số vị trí của tuyến trùng và tiêu diệt chúng bằng việc sản xuất ra một số enzyme trong đó có chitinase [2]. Mục đích của nghiên cứu này là tinh sạch, xác định hoạt tính chitinase ngoại bào của Paecilomyces sp. P1. Chitinase ngoại bào được định tính bằng phương pháp khuếch tán trên đĩa thạch với thuốc thử Lugol. Hoạt tính chitinase được xác định bằng phản ứng tạo ra $N$-acetyl glucosamine và đo tại bước sóng $540 \mathrm{~nm}$. Bằng việc sử dụng phương pháp tủa $\left(\mathrm{NH}_{4}\right)_{2} \mathrm{SO}_{4}$ bão hòa ở nồng độ $65 \%$, sắc khí trao đổi ion DEAE A-50 và điện di SDS-PAGE nồng độ $12,5 \%$; phân tử chitinase ngoại bào có trọng lượng gần $50 \mathrm{kDa}$, hoạt độ riêng 133,3 U/mg, độ tinh sạch gấp 2,1 lần so với ban đầu. Bằng phương pháp thử nghiệm với tuyến trùng Meloidogyne sp., khả năng tiêu diệt tuyến trùng của Paecilomyces sp. $\mathrm{P} 1$ đạt hiệu suất $58 \%$ trong vòng 96 giờ. Các kết quả trên là cơ sở khoa học nhằm ứng dụng Paecilomyces sp. $\mathrm{P} 1$ trong sản xuất chế phẩm sinh học diệt tuyến trùng.

Tù khóa: Paecilomyces sp.; chitinase, tinh sạch, kiểm soát sinh học, Melodogine sp.,

\section{Mở đầu}

Nấm sợi Paecilomyces sp., một loại nấm trong đất, được biết đến như là một loài có khả

\footnotetext{
*Tác giả liên hệ.

Địa chi email: buithivietha@gmail.com https://doi.org/10.25073/2588-1140/vnunst.4851.
}

năng diệt tuyến trùng hiệu quả gây bệnh cho cây. Paecilomyces cho thấy tiềm năng như là một tác nhân kiểm soát sinh học của tuyến trùng ký sinh thực vật và hiện đang được áp dụng trong các lĩnh vực trên thế giới [3]. Các công bố của Khan và cộng sự, Perveen $Z$. và cs., về cơ chế diệt tuyến trùng, Paecilomyces sp. thuộc loài nấm ký sinh trứng tuyến trùng. 
Bào tử của chúng có khả năng nhận biết và bám dính vào trứng của tuyến trùng, bào tử nảy mầm và sản sinh ra một số loại enzyme trong đó có chitinase, protease, collagenase... [1, 4]; Một số các nghiên cứu chỉ ra rằng chitinase từ Paecilomyces làm giảm lớp dày nhất của vỏ trứng tuyến trùng $[5,6]$, chitinase ngoại bào là một trong enzyme liên quan đến quá trình diệt tuyến trùng.

Hiện nay có khoảng 700 loài nấm diệt tuyến trùng được nghiên cứu. Về cơ chế phân tử diệt tuyến trùng: Một số nấm hình thành bẫy, vòng thắt để bắt và diệt tuyến trùng từ bên ngoài (ví dụ các chi Arthrobotrys, Drechslerella, Orbilia...); Một số nấm ký sinh bên trong tuyến trùng sử dụng một số loại enzyme như protease, chitinase, collagenase... (ví dụ các chi Paecilomyces, Pochonia, Lecanicillium, Cordyceps...; Một số nấm tiết ra độc tố để tiêu diệt tuyến trùng (ví dụ các chi Pleurotus, Coprinus...) [7-9].

Chitin, polymer $\mathrm{N}$-acetylglucosamine liên kết $\beta-1,4$, là polyme có nhiều thứ hai trong tự nhiên và cũng là thành phần cấu tạo phổ biến $(40 \%$ w/w) của vỏ trứng tuyến trùng. Chitinase còn được sử dụng để diệt các loài nấm và côn trùng hại thực vật khác; Ở một số loài Serratia spp., Baeuveria bassiana, Verticillium lecanii, chitinase có thể gây độc đối với côn trùng và nấm bệnh. Chitinase từ Trichoderma atroviridae được sử dụng để kiểm soát sinh học bệnh sâu hại khoai tây $[2,10]$. Ngoài ra, chitinase còn ức chế quá trình nảy mầm của bào tử nấm bệnh, sự kéo dài của sợi nấm [11].

Chitinase từ Trichoderma đã được xác định hoạt tính, nhân dòng và biểu hiện, đồng thời được thử nghiệm tiêu diệt tuyến trùng khác [3, 12]. Các vỏ trứng của tuyến trùng có bản chất là protein và biểu bì đóng vai trò là lớp bảo vệ hiệu quả chống lại sự xâm nhập của vi sinh vật trong đất. Các tác nhân sinh học ngoại lai có thể tấn công vào một vài vị trí trên tuyến trùng, chúng có khả năng tiết một số enzyme như chitinase, protease... Một số phân tử chitinase có trọng lượng 33, 43,5, 45 và $60 \mathrm{kDa}$ từ Metarhizium anisopliae; chitinase 45,0 kDa từ Beauveria bassiana đã được tinh sạch [13, 14]; chitinase có kích thước $52 \mathrm{kDa}$ từ Paecilomyces lilacinus; $43 \mathrm{kDa}$ từ Pochonia chlamydosporium (Verticillium chlamydosporium) và $P$. suchlasporium được tinh sạch và nghiên cứu để làm rõ vai trò của chúng trong tiêu diệt tuyến trùng.

Trong bài báo này, chúng tôi đưa ra kết quả về tinh sạch, xác định hoạt tính, trọng lượng phân tử chitinase từ Paecilomyces sp. P1. Kêt quả của bài báo cũng đưa ra khả năng diệt tuyến trùng của $\mathrm{P} 1$ và tiềm năng ứng dụng chúng trong sản xuất chế phẩm diệt tuyến trùng.

\section{Vật liệu và phương pháp nghiên cứu}

\subsection{Vật liệu: Paecilomyces sp. P1 tù bộ suu tập chủng của phòng Công nghệ lên men - Viện Công nghệ sinh học}

Tuyến trùng bướu rễ Meloidogyne sp.: Viện Sinh thái và tài nguyên sinh vật /Viện HL KH\&CN Việt Nam cung cấp.

\subsection{Phưong pháp}

Phương pháp nuôi cấy và lưu giữ chủng nấm sợi: P1 được lưu giữ trên môi trường PDA (Potato Dextrose Agar) thạch nghiêng, bảo quản ở nhiệt độ $4^{\circ} \mathrm{C}$ (theo Nguyễn Lân Dũng và cs., 1994)

Nuôi cấy thu dịch enzyme thô: Paecilomyces $\mathrm{P} 1$ được nuôi cấy trên môi trường PDB (Potato Dextrose Broth) ở $30^{\circ} \mathrm{C}-32^{\circ} \mathrm{C}$; thời gian nuôi cấy 3-5 ngày, tốc độ lắc 250 v/phút. Ly tâm $10000 \mathrm{v} / \mathrm{p}$ bỏ tủa.

Định tính khả năng sinh chitinase được xác định bằng phương pháp khuếch tán đĩa thạch. Cơ chất là chitosan đã thủy phân $0,5 \%$; độ dày thạch khoảng $0,5 \mathrm{~cm}$, đục lỗ với đường kính 0,5 $\mathrm{cm}$. Dịch enzyme thủy phân được đưa vào giếng và được nhuộm bằng thuốc thử Lugol $1,0 \%$. Nguyên tắc: Khi tác dụng với thuốc thử Lugol, phần môi trường trong suốt (vòng phân giải) phản ánh hoạt tính chitinase của chủng.

Xác định hoạt tính chitinase: được xác định bằng phản ứng màu với $\operatorname{DNSA}(3,5$ dinitrosalicylic acid) theo Miller G.L., 1959. 
Tinh sạch chitinase: dịch nuôi cấy được ly tâm 10000 v/phút loại bỏ sinh khối tế bào; được tủa với $\left(\mathrm{NH}_{4}\right)_{2} \mathrm{SO}_{4}$ bão hòa ở nồng độ $65 \%$; sau ly tâm, tủa được hòa với đệm Natri phot phat $50 \mathrm{mM}$ pH 7,0 thẩm tích loại muối ở $4^{\circ} \mathrm{C}$. Sau thẩm tích được đưa qua cột sắc ký trao đổi ion DEAE-Sephadex A-50 $(2,6 \times 60 \mathrm{~cm})$ đã được cân bằng với $150 \mathrm{ml}$ đệm Tris $\mathrm{HCl} 50 \mathrm{mM} ; \mathrm{pH}$ 7,0; tốc độ chảy là $30 \mathrm{ml} /$ giờ. Thể tích mỗi phân đoạn là $1,5 \mathrm{ml}$. Hàm lượng protein và hoạt tính enzyme được xác định tại mỗi phân đoạn, sau đó điện di trên gel polyacrylamide $12,5 \%$ để kiểm tra độ tinh sạch.

Xác định hàm lượng protein tổng số: Hàm lượng protein được xác định theo phương pháp Bradford.

Điện di trên gel polyacrylamide (SDS PAGE): được sử dụng theo phương pháp của Laemmli, 1970.

Phương pháp lây nhiễm nấm lên tuyến trùng (Alamgir, 2006): Nuôi nấm trên môi trường $\mathrm{PDA}$, lắc trong 7 ngày $\mathrm{ơ}^{\circ} 30^{\circ} \mathrm{C}, 200$ vòng/phút. Thu dịch nuôi cấy, bổ sung 300 con tuyến trùng $/ 5 \mathrm{ml}$ dịch trong hộp chuyên dụng, giữ trong 96 giờ ở $30^{\circ} \mathrm{C}$, kiểm tra số lượng tuyến trùng sau mỗi 24 giờ, mẫu đối chứng được thay dịch nuôi cấy nấm bằng nước cất. Làm tiêu bản nhuộm với Phloxin $\mathrm{B}$ và soi dưới kính hiển vi để xác định số lượng tuyến trùng chết bắt màu tím với thuốc nhuộm.

Phương pháp thu và đếm tuyến trùng [15]: Tuyến trùng được đếm và tính số lượng bằng đĩa đếm tuyến trùng (counting dish) và đồng hồ đếm (counting machine) dưới kính hiển vi soi nổi. Trong trường hợp mẫu có ít tuyến trùng $(<1000)$ có thể đổ cả tuyến trùng vào đĩa để đếm. Sau khi lắc nhẹ cho dung dịch tuyến trùng dàn đều, có thể đếm toàn bộ tuyến trùng theo các dãy ô cho toàn bộ đĩa đếm hoặc có thể đếm đại diện một số ô hoặc dãy, sau đó tính trung bình 1 ô và nhân với tổng số ô trong đĩa. Trong trường hợp mẫu có quá nhiều tuyến trùng thì ta có thể pha loãng dung dịch tuyến trùng thành $50 \mathrm{ml}$, sau đó lấy $10 \mathrm{ml}$ để đếm, lặp lại lần 2 như vậy, tính trung bình số lượng tuyến trùng trên $10 \mathrm{ml}$ và nhân với 5 .

\section{Kết quả và thảo luận}

\subsection{Khả năng sinh chitinase của Paecilomyces sp. $P 1$}

Nhằm định tính chitinase, chúng tôi nuôi cấy lắc $\mathrm{P} 1$ trên môi trường $\mathrm{PDB}$ (mục 2.1) có bổ sung chitin huyền phù $0,5 \%$. Sau $96 \mathrm{~h}$, dịch nuôi cấy được nhỏ trên đĩa thạch được nhuộm bằng Lugol $0,1 \%$. Kết quả được trình bày ở hình 3.1 .
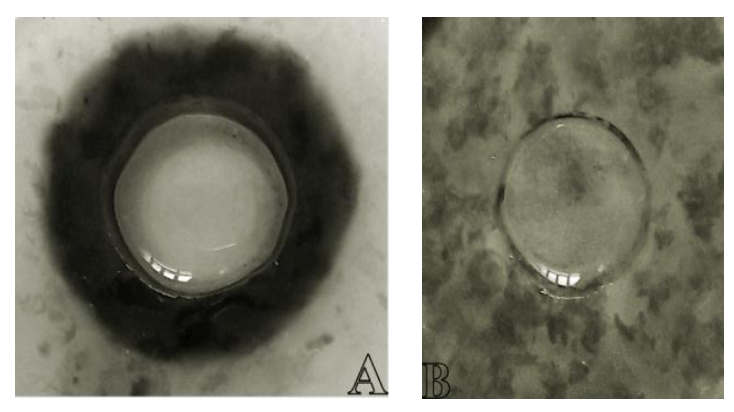

Hình 3.1. Khả năng sinh chitinase của Paecilomyces sp. P1.

(A: Thí nghiệm; B: Đối chứng)

Trên hình 3.1 cho thấy, $\mathrm{P} 1$ có khả năng sinh chitinase với vòng phân giải $12 \mathrm{~mm}$ trên môi trường có bổ sung chitinase $0,5 \%$ làm cơ chất cảm ứng, do vậy chitinase từ $\mathrm{P} 1$ là chitinase ngoại bào. Theo công bố của Perveen và Shahzad, 2013; Khan Alamgir và cs., 2003; Kopparapu và cs., 2012 [1, 4, 16] , nghiên cứu hoạt tính chitinase từ các loài thuộc Paecilomyces và thử nghiệm tuyến trùng gây hại cây cà phê, cà chua ... cho thấy chúng có khả năng tiêu diệt tuyến trùng. Từ những kết quả này, Paecilomyces được ứng dụng trong kiểm soát sinh học bệnh thực vật. Với khả năng sinh chitinase ngoại bào của $\mathrm{P} 1$, chúng tôi tiếp tục tiến hành những nghiên cứu tiếp theo như tinh sạch chitinase, thử nghiệm khả năng diệt tuyến trùng...

\subsection{Tinh sach chitinase tì Paecilomyces sp. Pl}

Nuôi cấy thu nhận chitinase: Từ những kết quả nghiên cứu, tham khảo và lựa chọn môi 
trường nuôi cấy, chúng tôi sử dụng môi trường PDA pH 7, thu nhận enzyme sau 96 h. Chitinase sinh ra từ Paecilomyces cũng như các chủng nấm sợi khác thường có độ tinh khiết không cao do tạp lẫn nhiều protein khác. Vì vậy, quá trình tinh sạch để thu được chitinase tinh khiết là cần thiết. Kết quả này phục vụ cho quá trình đánh giá các yếu tố ảnh hưởng tới hoạt tính enzyme và sử dụng chúng cho những ứng dụng trong thực tế.

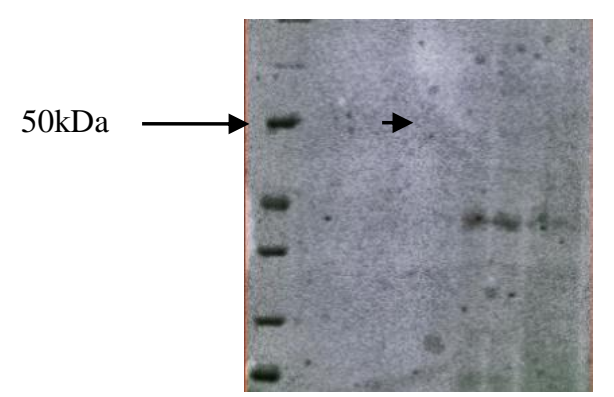

Hình 3.2. Điện di SDS-PAGE của chitinase tinh sạch từ Paecilomyces $\mathrm{P} 1$.
Sau khi khảo sát quá trình tinh sạch chitinase từ Paecilomyces sp. $\mathrm{P} 1$, tiến hành tinh sạch chitinase bằng $\left(\mathrm{NH}_{4}\right)_{2} \mathrm{SO}_{4}$ bão hòa $65 \%$. Hoạt tính chitinase sau tinh sạch thu được 85,08 $\mathrm{U} / \mathrm{mg}$, độ sạch 1,35 lần và hiệu suất thu hồi đạt $11,6 \%$. Chitinase sau thẩm tích loại muối được đưa qua cột DEAE - Sephadex A-50 và cuối cùng cho độ sạch 2,1 lần và hiệu suất thu hồi đạt $1,68 \%$. Enzyme tinh sạch này có hoạt tính 133,3 U/mg (Bảng 3.2), sản phẩm sau tinh sạch được xác định khối lượng phân tử bằng SDSPAGE $12,5 \%$. Kết quả được trình bày ở Bảng 3.2.

Bảng 3.2. Kết quả tinh sạch chitinase từ chủng Paecilomyces sp. $\mathrm{P} 1$

\begin{tabular}{llllll}
\hline Bước tinh sạch & $\begin{array}{l}\text { Hàm lượng } \\
\text { protein TS }(\mathrm{mg})\end{array}$ & $\begin{array}{l}\text { Hoạt tính } \\
\text { tống số }(\mathrm{U})\end{array}$ & $\begin{array}{l}\text { Hoạt độ riêng } \\
(\mathrm{U} / \mathrm{mg})\end{array}$ & $\begin{array}{l}\text { Độ sạch } \\
\text { (lần) }\end{array}$ & $\begin{array}{l}\text { Hiệu suất } \\
(\%)\end{array}$ \\
\hline Enzyme thô & 0,76 & 47,6 & 62,63 & 1,0 & 100 \\
$\left(\mathrm{NH}_{4}\right)_{2} \mathrm{SO}_{4}$ & 0,065 & 5,53 & 85,08 & 1,35 & 11,6 \\
DEAE-Sephadex A-50 & 0,006 & 0,8 & 133,3 & 2,1 & 1,68 \\
\hline
\end{tabular}

Chitinase từ Trichodesma harizanum $[14,17]$ đã được tinh sạch bằng tủa muối $\left(\mathrm{NH}_{4}\right)_{2} \mathrm{SO}_{4}$ bão hòa, DEAE-Sephadex A-50, cho hoạt tính tương đương chitinase của nghiên cứu này (133,3 U/mg); nhưng lại thấp hơn Lecanicillium lecanii $43 \mathrm{H} \quad 0,35$ lần [18]; thấp hơn so với Metarhizium anisopliae gần 5 lần. Hiệu suất tinh sạch của nghiên cứu này là thấp nhất và thấp hơn so với nghiên cứu của Nguyễn Hữu Quân và cộng sự là 0,3 lần. Đây cũng là bước đầu thành công bởi quá trình tinh sạch này còn chưa được nghiên cứu tối ưu các điều kiện.

Trên Hình 3.2 cho thấy: chitinase điện di cho băng có kích thước khoảng $46 \mathrm{kDa}$. Nghiên cứu của Chen, 2005, chitinase được tinh sạch có trọng lượng phân tử khoảng $23 \mathrm{kDa}$; theo nghiên cứu của $\mathrm{Li}, 2015, P$. lilacinus có trọng lượng phân tử 45,8 kDa còn Paecilomyces sp. $\mathrm{P} 1$ được đưa vào nghiên cứu, chitinase có trọng lượng là khoảng $46 \mathrm{kDa}$. Theo nghiên cứu của Van Nam Nguyen, 2009 [19], Paecilomyces có trọng lượng là $32 \mathrm{kDa}$ (Chi32) và $46 \mathrm{kDa}$ (Chi46) và được xác định Chi32 là chitinase nội bào và Chi46 là chitinase ngoại bào. Từ các kết quả trên, chitinase từ Paecilomyces sp. $\mathrm{P} 1$ là chitinase ngoại bào và $\mathrm{P} 1$ cần được thử nghiệm khả năng diệt tuyến trùng.

\subsection{Thử nghiệm khả năng diệt tuyến trùng của P1}

Với mục đích thử nghiệm khả năng diệt tuyến trùng của Paecilomyces $s p$. $\mathrm{P} 1$, chúng tồi tiến hành theo phương pháp như mục 2 . 
Bảng 3.3. Kết quả khảo sát khả năng diệt tuyến trùng của dịch nuôi cấy Paecilomyces $\mathrm{P} 1$

\begin{tabular}{llccccc}
\hline \multirow{2}{*}{ STT } & Tên chủng & \multicolumn{3}{c}{ Tỉ lệ tuyến trùng chết $(\%)$} & & \\
\cline { 3 - 6 } & & 24 giờ & 48 giờ & 72 giờ & 96 giờ & 120 giờ \\
\hline 1 & Đối chứng (không có nấm) & - & - & - & - & - \\
2 & Paecilomyces sp. P1 & - & 10,81 & 30,7 & 58,5 & 58,5 \\
\hline
\end{tabular}

Ghi chú: (-) Không tiêu diệt.

Kết quả bảng 3.3 cho thấy, chủng nấm P1 sau $72 \mathrm{~h}-96 \mathrm{~h}$ thử nghiệm lượng tuyến trùng bướu rễ Meloidogyne sp. bị tiêu diệt là 58,5\%.; thời gian từ $96 \mathrm{~h}$ đến $120 \mathrm{~h}$ do hoạt tính enzyme của dịch thử nghiệm giảm do vậy tỷ lệ tuyến trùng chết không tăng lên. Đối với Paecilomyces sp. là loại nấm ký sinh do đó hiệu quả thử nghiệm cho kết quả sau 72-96 h [4, 20], kết quả này cũng trùng với các công bố của Ajrami và cs., 2016 khi thử nghiệm Paecilomyces lilacinus với tuyến trùng Meloidogne javanica gây bướu rễ cây Cà chua; ở 72 - 96 h diệt được 57\% [21]. Paecilomyces lilacinus YES-2 và $P$. chlamydosporia HDZ-9 được chọn từ các thử nghiệm in vitro được bào chế trong các viên alginate và được đánh giá để kiểm soát tuyến trùng Meloidogyne incognita trên Cà chua trong nhà kính; Các viên $P$. lilacinus với tỷ lệ cao nhất $(1,6 \%)$ làm giảm mật độ rễ $66,7 \%$. Các viên $P$. chlamydosporia đã làm giảm $90 \%$ mật độ tuyến trùng cuối cùng; Chứng tỏ rằng, $P$. lilacinus và $P$. chlamydosporia dưới dạng bào chế có thể kiểm soát hiệu quả tuyến trùng Meloidogyne sp.

Ngoài ra, nghiên cứu của Perveen và Shahzad, sử dụng dịch thể nuôi cấy $P$. lilacinus; $P$. variotii; P. fumosoroseus ủ với ấu trùng của tuyến trùng $M$. incognita; sau 24,48 , 72 giờ đếm số lượng ấu trùng; Kết quả cho thấy sau 72 giờ khả năng diệt tuyến trùng với hiệu quả $75 \%$ [4].

Kết quả thử nghiệm tuyến trùng của $\mathrm{P} 1$ cho thấy: có thể sử dụng chủng nấm trên cho ứng dụng kiểm soát tuyến trùng bướu rễ hại cây trồng. Tuy nhiên, cần có nghiên cứu sâu hơn nhằm nâng cao hoạt tính và điều kiện nuôi cấy thích hợp.

\section{Kết luận}

Paecilomyces sp. P1 có khả năng sinh chitinase ngoại bào; Hoạt tính chitinase được xác định bằng phương pháp DNS và đo tại bước sóng $540 \mathrm{~nm}$. Bằng việc sử dụng phương pháp tủa $\left(\mathrm{NH}_{4}\right)_{2} \mathrm{SO}_{4}$ bão hòa ở nồng độ $65 \%$, sắc khí trao đổi ion DEAE $\mathrm{A}-50$ và điện di SDS-PAGE nồng độ $12,5 \%$; phân tử chitinase có trọng lượng gần $50 \mathrm{kDa}$, hoạt độ riêng 133,3 $\mathrm{U} / \mathrm{mg}$, độ tinh sạch gấp 2,1 lần so với ban đầu.

Bằng phương pháp thử nghiệm lây nhiễm tuyến trùng Meloidogyne sp. với dịch thể Paecilomyces sp. P1, hiệu suất đạt $58 \%$ trong vòng 96 giờ. Đây là kết quả nghiên cứu ban đầu, là cơ sở cho nghiên cứu chế phẩm diệt tuyến trùng sau này.

\section{Tài liệu tham khảo}

[1] Khan Alamgir, Williams Keith, Mark P. Molloy, and Nevalainen Henlena, Purification and characterization of a serine protease and chitinases from Paecilomyces lilacinus and detection of chitinase activity on 2D gels, Protein Expression and Purification. 32 (2003) 210.

[2] Khadijeh Abbsi, Doustmorad ZAFARI, Robert WICK., Evaluation of chitinase enzyme in fungal isolates obtained from golden potato cyst nematode Globodera rostochiensis ZemdirbysteAgriculture. 2 (2017) 179.

[3] F. A. Zaki, D. S. Bhatti, Effect of castor (Ricinus communus) and the biocontrol fungus Paecilomyces lilacinus on Meloidogyne javanica, Nematologica. 36 (1980) 114.

[4] Z. Perveen, S. Shahzad, A comparative study of the efficacy of Paecilomyces species against rootknot nematode Meloidogyne incognita. Pakistan Journal of Nematology. 31 (2013) 125. 
[5] P.J.M. Bonants, P.F.L. Fitters, H. Thijs, E. den Belder, C. Waalwijk, J.W.D.M. Henfling. A basic serine protease from Paecilomyces lilacinus with biological activity against Meloidogyne hapla eggs, Microbiology. 141 (1995) 75.

[6] D. Wharton,. Nematode eggshells, Parasitology. 81 (1980) 447.

[7] C.M Baratto, V. Dutra, J.T. Boldo, L.B. Leiria, MH Vainstein, A. Schrank Isolation, characterization and transcriptional analysis of the chitinase chi2 gene (DQ011663) from the biocontrol fungus Metarhizium anisopliae var. anisopliae., Curr Microbiol. 53 (2006) 217.

[8] Van Nam Nguyen, Y.J Kim, K.T Oh, W.J. Jung, R. D Park, The antifungal activity of chitinases from Trichoderma aureoviride DY-59 and Rhizopus microsporus VS-9. Curr. Microbiol. 56 (2008) 28.

[9] V. E Tikhonov, L.V Lopez-Llorca, J Salinas, H. B. Jansson . Purification and characterization of chitinases from the nematophagous fungi Verticillium chlamydosporium and V. suchlasporium, Fungal Genet Biol, 2002, 67.

[10] R.J. Leger St , R.M. Cooper, A.K. Charnley, Characterization of chitinase and chitobiase produced by the entomopathogenic fungus Metarhizium anisopliae. J. Invertebr. Pathol. 58 (1991) 415.

[11] R.S. Patil, V. Ghormade, M.V. Desphande, Chitinolytic enzymes: an exploration. Enzyme Microb. Technol. 26 (2002) 473.

[12] J.L.D. Marco, M.C. Valadares-Inglis . Purification and characterization of an Nacetylglucosaminidase produced by a Trichodermaharzianum strain which controls Crinipellis perniciosa. Appl. Microbiol. Biotechnol. 64 (2003) 70.

[13] S. Leger, R.J. Joshi, R.J. Bidochka, D.W. Roberts. Characterization and ultrastructural localization of Metarhizium anisopliae, $M$. xavoviride, and Beauveria bassiana during fungal invasion of host
(Manduca sexta) cuticle. Appl Environ Microbiol 62 (1996) 907.

[14] S.C Kang, S. Park, D.G Lee, Purification and characterization of a novel chitinase from the entomopathogenic fungus, Metarhiziumanisop liae. J Invertebr Pathol. 73 (1999) 276.

[15] Nguyễn Ngọc Châu, Tuyến trùng thực vật và cơ sở phòng trừ, NXB Khoa học Kỹ thuật, Hà Nội, 2003.

[16] Kopparapu Narasimha Kumar, Peng Zhou, Shuping Zhang, Qiaojuan Yan, Zhuqing Liu, Zhengqiang Jiang, Purification and characterization of a novel chitinase gene from Paecilomyces thermophila expressed in Escherichia coli. Carbonhydrate Reseach. 347 (2012) 155.

[17] J. De la Cruz, A. Hidalgo-Gallego, J.M. Lora, T. Benitez, J.A. Pintor-Toro, A. Llobell , Isolation and characterization of three chitinases from Trichoderma harzianum., Eur. J. Biochem. 206 (1992) 859.

[18] Nguyễn Hữu Quân, Vũ Văn Hạnh, Quyền Đình Thi, Phạm Thị Huyền, Tỉnh sạch và đánh giá tính chất lý hóa của chitinase từ nấm Lecanicillium lecanii, Kỷ yếu Hội nghị Công nghệ Sinh học toàn quốc. 1 (2013) 426.

[19] Van Nam Nguyen, In-Jae Oh, Young-Ju Kim, KilYong Kim, Young-Cheol Kim, Ro-Dong Par J Ind., Purification and characterization of chitinases from Paecilomyces variotii DG-3 parasitizing on Meloidogyne incognita eggs. (2009) 195

[20] Methanee Homthong, Anchanee Kubera, Matana Srihuttagum, Vipa Hongtrakul, Isolation and characterization of chitinase from soil fungi, Paecilomyces sp. Agriculture and Natural Resources. 1 (2016) 50.

[21] H. M. Hussein Al Ajrami., Evaluation the Effect of Paecilomyces lilacinus as a Biocontrol Agent of Meloidogyne javanica on Tomato in Gaza Strip, Faculty of science Master of Biological Sciences Microbiology, 2016. 